\title{
Not So Digital After All? A Look at the Nature of Digital Nudging through the Prism of the Digital Object Concept
}

\author{
Marcin Bartosiak \\ University of Pavia \\ marcin.bartosiak@unipv.it
}

\begin{abstract}
Digital nudging is an effective way to influence individuals' behavior when they interact with digital computers. However, scholars only partially discussed how digital technology transforms nudging mechanisms in digital choice environments. Considering the recently proposed research agenda on digital objects, studying the 'digital' component of digital nudging can help to understand how the 'digital' transforms the phenomenon of nudging and creates new, digital-only methods of influencing individuals' behavior. This paper investigates the current state of the literature on the context of digital nudging and discusses the role of digital objects in nudging with examples of how digital properties can transform the mechanisms of nudging.
\end{abstract}

\section{Introduction}

There is a general agreement in the literature that digital nudging is an effective way to influence individuals' choices when they interact with digital computers $[1,2,3]$. The term 'nudge' coined by Thaler and Sunstein [4:6] means 'any aspect of the choice architecture that alters people's behavior in a predictable way without forbidding any options or significantly changing their economic incentives.' The choice architecture is the designed context in which people make decisions - namely a manipulated choice environment. Information Systems (IS) scholars introduced the term 'digital nudging' to investigate nudges enabled by digital technology $[5,6]$, defining it originally as the "use of user-interface design elements to guide people's behavior in digital choice environments" [6]. However, to date, scholars have only partially discussed the role or purpose that digital technology has in the transformation of nudging in digital choice environments, compared to those in 'physical' environments [2]. The role of technology seems to be limited to a facilitator and a bearer of nudges. It is seen mainly as an information processing tool that alters and enhances the ways that individuals process information - a relatively unproblematic computing resource to which researchers pay little conceptual attention [7].

Recent works in IS highlight the proliferation of digital objects conceptualized as 'objects whose component parts include one or more bitstrings' [8:7] and distinguish their properties from IT objects $[8,9$, $10]$. Being non-material and computable by nature, such objects possess properties that cannot be replicated in the physical world. Yet, they do transform everyday activities and familiar artifacts so that they actively shape individuals' experiences in physical environments [11]. Considering the recently proposed research agenda focused on digital objects [9], understanding the 'digital' component of digital nudges and digital choice environments will help the topic not only to stay relevant in the world where 'digital' stops reflecting the 'physical' but actually shapes it. It will also help to understand how the 'digital' component of digital nudging transforms the phenomenon and creates new, digital-only methods of influencing individuals' behavior.

This paper investigates the current state of the literature on digital nudging through the prism of digital objects concept. It aims at answering the following research question: What is the role of digital objects in transforming the phenomenon of nudging in digital choice environments? Thus, the goal of the study is not to analyze the results of previous works and the effect of nudging on individuals. Rather, unlike previous reviews, the focus here is on investigating the conceptualization of the technology behind digital nudging. The paper offers a theoretical contribution to the digital nudging literature by placing digital nudges and digital choice environments in the current debate on digital objects. Furthermore, the paper presents how digital object properties can transform the nudging process.

The remainder of the paper is organized as follows. First, we present a conceptual background, focusing on digital nudging, choice environment, and digital objects. Second, we outline the methodology of the literature review, followed by the results - we summarize the 
context of digital nudging, and we present how the literature understands the 'digital' component of nudging. Finally, the discussion presents a conceptualization of digital nudging from the perspective of the digital object concept, with examples of how digital properties can transform nudging.

\section{Conceptual background}

\section{1. (Digital) nudging}

Nudging theory posits that it is possible to present a choice in a way that individuals are 'nudged' toward options that are more beneficial for them or society in general. The underlying idea, called libertarian paternalism, assumes that the designer can plan choice architecture so that the more beneficial option becomes more salient or convenient and an individual facing the choice is more likely to select it while still enjoying the freedom of choice [4]. It is possible because of the existence of two types of cognitive processes present in human decision-making [12]. Cognitive operations derived from intuition (or System 1) are automatic and effortless, whereas the operations based on reasoning (or System 2) are deliberately controlled and, thus, more effortful [12]. Due to limited capacity for cognitive effort, System 2 processes disrupt each other, while System 1 processes do not affect each other when combined with other tasks [13]. Because of its automaticity, decisions made through System 1 tend to be based on the current stimulus, rather than reasonable thinking [12]. The idea is derived from Simon's concept of bounded rationality - individuals' decision-making rationality is limited by and related to the environment in which the organism exists [14]. Nudging addresses mainly System 1 processes and their characteristics.

IS scholars study 'digital' nudging in consequence of everyday life being pervasively mediated by computing technologies [11], where individuals increasingly interact with digital objects, digital phenomena, and digital practices $[15,16]$. The most ample definition of digital nudge defines it as "any intended and goal-oriented intervention element (e.g. design, information or interaction elements) in digital or blended environments attempting to influence people's judgment, choice, or behavior in a predictable way, that (1) is made possible because of and works by making use of cognitive boundaries, biases, routines, and habits in individual and social decision-making, (2) works by making use of those cognitive boundaries, biases, routines, and habits as integral parts of such attempts, (3) preserves the full freedom of choice without forbidding or adding any rationally relevant choice options, (4) does not limit the choice set or making alternatives appreciably costlier in terms of time, trouble, social sanctions, and so forth, (5) nudgees must be able to easily recognize when and where they are subject to being nudged (type-transparency), as well as what the nudger's goals of this intervention are, in addition to how and why the nudge is working (tokentransparency), and (6) increases the private welfare of the nudged individual (pro-self) or the social welfare in general (pro social)" [1:11]. This view emphasizes the role of cognitive boundaries in digital nudging. It also underlines freedom of choice and transparency as important ethical factors in digital nudging. However, it does not put much focus on the role of digital technology in the phenomenon of digital nudging. Rather, it refers to it as a context where the process of nudging and decision-making happens, calling it 'digital environments' and juxtaposing it with 'blended environments.' It does not explain, however, what the role of 'digital' in digital nudging is or how it affects the changes to the choice environment and the process of nudging itself.

\subsection{Choice environments}

Choice is commonly understood as an act of choosing or selecting from a set of available options. In the classic economic theories, an individual is assumed to always know their preference and to always make a choice to maximize the utility of its outcomes, due to rational decision making [17]. Thus, in classic economic terms, the choice is considered as a process of maximization, in which rational decisions lead to better outcomes [18]. Nudge theory is founded on the premise that, unlike the rational 'homo economicus' or 'econs', individuals often make choices based on the intuitive response to the choice environment in which the decision should be made [19]. Referring to bounded rationality, individuals adapt to the environment's properties that can simplify choice mechanisms [14]. Thus, one can alter individuals' decisions by making small and inexpensive changes to the environment in which the decisions and judgments are made [20]. Given the importance of the choice environment in decisionmaking, the behavior of individuals rarely results from what they are able to compute. Rather, it is a derivative of what they see at a given moment [21]. Thus, in the case of artificial choice environments, to enhance human interactions with them, one can either use the technology to re-create the physical environment or emphasize the cognitive process of the users' experience [22].

In the context of nudging, a choice environment is composed of 'all elements and aspects of the choice situation that the decision-maker can encounter in her physical or virtual surroundings, perceive through her senses, or interact with' [23:72]. In this view, the 
elements of the choice environments shall be understood as signifiers. The content of all messages (signified) is less important in the design of the choice environment. Further, the nudged choice itself is strongly affected by the complexity of the elements of the choice environment in which the behavior takes place [24]. In nudge theory, the way one organizes these elements to influence individuals' decisions is called 'choice architecture' [4]. The choice environment is rarely neutral and choice architects always shape decisions, even unintentionally [25]. For example, simply changing the positioning of healthy food products on the shelves to be more visible and accessible to customers, sways their shopping decision towards them and, thus, increases the consumption of healthy food [26]. Choice environments on screens can have similar effect. For example, a pop-up window with a share button on a website may increase the number of shares of that website [27].

\subsection{Digital objects, phenomena, and environments}

Originally, the term 'digital' referred to devices being a discrete representation of electric signals and data [28]. Nowadays, the term 'digital' is associated with objects and phenomena (e.g., digital nudging) in which digital computers play a central role [16]. Scholars of various backgrounds tried to define digital objects and phenomena by looking at them from different perspectives. Depending on the focus of analysis, digital objects (phenomena) can be understood as shapes (activities) appearing on a screen ${ }^{1}$, strings of binary code running software, or series of electric signals produced by voltage and the operation of logic gates [29:2].

In the narrow meaning, digital objects have been understood as a reflection of their analog originals, created in the process of 'digitization'. Literature defines digitization as a technical 'process of converting analog signals into a digital form, and ultimately into binary digits' [30:749] or the business-oriented 'ability to turn existing products or services into digital variants, and thus offer advantages over tangible products' [31:6]. As such, digitization simply converts analog streams of information into digital ones. Broader (and often confused with digitization, thus, interchangeably used in everyday language) 'digitalization' is a subsequent step to digitization. Digitalization is a sociotechnical phenomenon and process of adopting and using digitizing techniques and digital technologies in broader individual, organizational, and societal contexts

\footnotetext{
${ }^{1}$ The "screen" reflects the fact that most human-computer interaction still happen through graphical user interfaces displayed
}

[30]. It affects all aspects of human life, from personal relationships and works to politics [32]. The meaning of the term 'digital' in this light is not limited to the fact that with growing computational power we can process larger amounts of data [33]. Rather, it shows that by operating with data, the system can establish connections and form a network of data that extends entity to entity communication, changing the usual relationships between them [29].

In the field of IS, digital objects are defined as any 'objects whose component parts include one or more bitstrings' [8:7]. Bitstrings - the sequences of 1's and 0 's used in computing to represent information - by nature are non-material. As a consequence, access to and engagement with them requires material or hybrid bearers [8]. For example, a piece of hardware (IT), cannot be considered digital if at least one of its components is not digital or, in other words, if they are not bearers of digital objects. Thus, practices and IT objects become digital when one or several of their constituents are digital [15]. Let's take a melody or a piece of music - a non-material and non-digital object. When one registers it with a digital computer (thus saves it as a sequence of bitstrings), it becomes a non-material digitized object. Such an object can become a building part of other digital objects (e.g. digital movies, computer games, software) or can be easily manipulated by digital computing devices. Furthermore, it can be accessed through multiple material digital devices in many places at the same time (e.g. when uploaded to streaming services like Spotify or iTunes). In this light, the term 'digital' refers to creating new usage possibilities and transforming everyday activities through the application of digital objects upon familiar artifacts [11].

Furthermore, IS scholars agree on the computed nature of digital objects $[8,9]$. Computation is a 'realtime process performed by digital computers that involve the algorithmic manipulation of information borne by bitstrings' [8:10]. The existence of digital objects depends on the process of computation. This property of the digital objects allows to combine and recombine existing non-material objects so that one achieves the desired outcomes [8, 34]. Thus, the computed nature of digital objects gives the potential to create new content from a whole new combination of sources [35]. Further, it has led to the recently proposed ontological reversal for IS research, which states that 'the non-physical digital version of the reality is not just as real as the physical version, it is more so' [9]. Digital and analog worlds are 'fused' in a way that digital objects, phenomena, and practices create, shape, and

on a screen. Thus, this definition could be extrapolated to non-screen user interfaces. 
transform the analog world. Objects like beacons, home assistants, autonomous cars, or the internet of things are material objects that acquired affordances previously not present in the physical world [36] - they are bearers of digital objects (and as such, become hybrid digital objects themselves) that collect inputs from and interact with their environment so that they actively shape individuals' experience in these environments [37, 38]. It is even possible that an object created with one function in mind acquires different system functions or that the way it is delivered to a user, changes due to input received from the environment - e.g. users' individual interests habits or plans $[8,35]$.

From this perspective, digital choice environments can be digital objects themselves and, as a consequence, they are easier, faster, and cheaper to scale [9, 34]. Furthermore, they can compose and be composed of other digital objects. Yet, the nature of digital choice environments as digital objects and their role as bearers of nudges seems ambivalent in the literature. On the one hand, Schneider and colleagues [39] question the effectiveness of some nudges in the digital choice environments, as they may not always be 'directly transferred to a digital context'. On the other, Lembcke and colleagues [1] call nudging 'digital specific phenomena' because, even if mirroring the physical world, digital choice environments are highly visual and, thus, are better suited for influencing people. This is because information overload is often higher in digital choice environments [40]. After all, the individuals have to manage the information flow and understand the information itself simultaneously [41]. As a consequence, individuals with limited elaboration likelihood (or cognitive power) have a lesser potential for successful information processing [42] and tend to make decisions faster, based mostly on heuristics and cognitive biases [1]. Furthermore, the growing proliferation of cognitive computing and artificialintelligence-based devices puts human-computer interactions in a new perspective and changes the way individuals interact with digital choice environments [43]. These interactions become more human-like and personalized, as the responses based on outputs from the cognitive algorithms adapt to individuals interacting with them [44].

\section{Methodology}

To summarize and discuss the current state of knowledge on the role of digital technology in digital nudging, we conducted a systematic literature review
[45]. We used the methodological framework by vom Brocke et al. [46] and followed categorization by Cooper [47] (Table 1). The focus of the review is on the applications and practices (the use of digital technology in digital nudging).

Table 1. Visualization and categorization approach [46, 47]

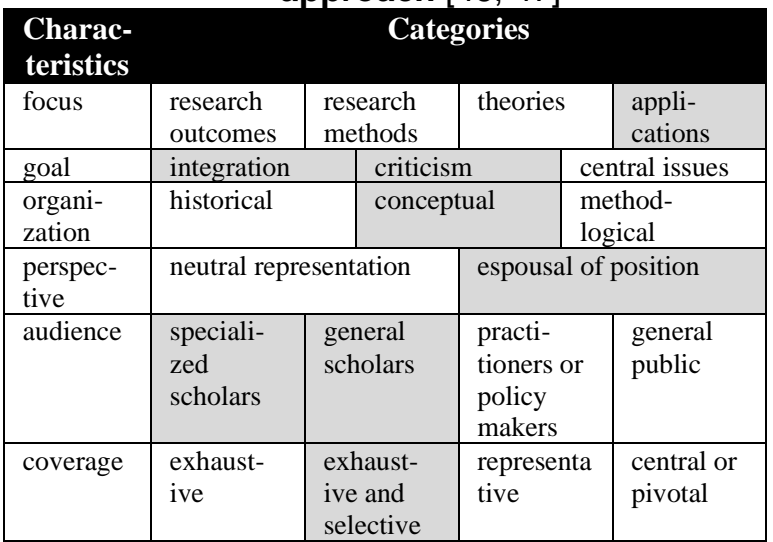

We used the latest edition of the ABS' Academic Journal Guide [48] as a base for the search. Specifically, we investigated all 93 journals included in the category 'Information Management' of the guide. Furthermore, we searched the main international IS conferences: HICSS, ICIS, AMCIS, ECIS, and PACIS. We excluded chapter and local conferences from the search, which is the main limitation of the study. Using AIS Electronic Library, Web of Science, ScienceDirect, JSTOR Archive, and INFORM Pubs we searched a disjunction of the following keywords: 'nudge,' 'nudging,' 'digital nudge,' 'digital nudging'. While we performed an exhaustive search in information systems journals and main conferences in the field, we applied a selective method of presentation following the selection criteria:

1. The article had to be published in one of the journals listed on the Academic Journal Guide or in the proceedings of main IS conferences.

2. The article had to be published between 2015 and $2020^{2}$.

3. The article had to study nudging in digital choice environments. Thus, this includes studies that mention nudging and use digital technologies as an enabler of nudging intervention.

4. The concept of nudging had to be used in the context of influencing individuals' choices. We excluded studies that use the term in a different context.

\footnotetext{
2 The first manuscript introducing digital nudging was published in 2015. The search was performed in the first quarter of 2021, when most 2021 papers were unavailable.
} 
5. The conceptualization of nudging had to fulfill the definition of nudging in that it does not forbid or add any rational choice option, change incentives significantly, or provide rational argumentation.

The initial search (criteria $1 \& 2$ ) yielded 150 journal articles and 214 conference proceedings publications of which we examined titles and abstracts. We excluded studies that did not refer to nudging literature or did not study nudges in digital choice environments (criterium 3). This step left 111 papers. In the full-text screening, we filtered articles based on the scope introduced earlier [45] (criteria 4 \& 5). The result was 88 works published in 25 journals and proceedings of five conferences.

As the focus of this review is not on research outcomes, the search was not limited to empirical studies. Thus, we did not filter out non-empirical studies, theoretical or conceptual studies, or works-inprogress. Additionally, after a backward and forward search, we included one article not included in the initial search. As a result, the review findings stem from the 89 articles remaining at this stage (Table 2).

Table 2. Articles screening process

\begin{tabular}{|c|c|c|c|c|}
\hline & $\begin{array}{l}\text { Initial } \\
\text { search }\end{array}$ & $\begin{array}{l}\text { Title \& } \\
\text { abstract } \\
\text { screening }\end{array}$ & $\begin{array}{l}\text { Full-text } \\
\text { screening }\end{array}$ & $\begin{array}{l}\text { Papers } \\
\text { in the } \\
\text { review }\end{array}$ \\
\hline Journals & 150 & 49 & 35 & 35 \\
\hline HICSS & 64 & 11 & 9 & \multirow{5}{*}{53} \\
\hline ICIS & 54 & 13 & 10 & \\
\hline AMCIS & 29 & 7 & 7 & \\
\hline ECIS & 50 & 24 & 22 & \\
\hline PACIS & 17 & 7 & 5 & \\
\hline $\begin{array}{l}\mathrm{B} / \mathrm{F} \\
\text { search }\end{array}$ & & & & 1 \\
\hline TOTAL & 364 & 111 & 88 & 89 \\
\hline
\end{tabular}

\section{Literature Review}

\subsection{Context of nudging}

The majority of works (76 papers) investigate digital nudging as a modification of interface elements displayed on various forms of screens (Table 3). Only one work introduces the idea of nudging through both graphical and voice interfaces in the context of interactions with human-like agents [49]. The authors discuss a need for understanding how anthropomorphic features of digital technology affect nudging and interactions between individuals and anthropomorphic smart devices. However, the idea has not been tested empirically.

In terms of devices used to bear the digital nudge, most of the studies use a traditional desktop computer as a technology to display the nudge. Fourteen studies investigated nudges on mobile devices (smartphones) and eight investigated digital nudging on both the desktop and smartphones. Only a few studies considered other types of technologies to present the digital nudge. Three studies investigated wearable devices - two papers used smartwatch game app to digitally nudge users to protect their privacy on the Web $[50,51]$ and the third study investigated digital nudges to support cardiac rehabilitation [52]. While the study focuses mostly on smartphone-enabled nudging, it discusses the enhancement of the nudge by the data coming from wearable health devices. Yet, the idea has not been tested empirically. One study introduces the previously mentioned idea of nudging through human-like agents [49]. Finally, one study uses augmented reality as a nudging environment [53]. While the paper focuses on testing nudges in augmented reality, it does not test the effect of technology itself. However, it does confirm the effect of nudges (specifically, customer recommendations) when presented in an augmented reality environment.

Table 3 Technology investigated in digital nudging papers

\begin{tabular}{|l|c|}
\hline Type of interface & Number of studies \\
\hline Screen & 76 \\
\hline Screen \& Voice & 1 \\
\hline Not specified & 12 \\
\hline Type of device & Number of studies \\
\hline Desktop & 39 \\
\hline Mobile & 14 \\
\hline Desktop \& mobile & 8 \\
\hline Wearable device & 3 \\
\hline Augmented reality & 1 \\
\hline Human-like agent & 1 \\
\hline Not specified & 23 \\
\hline
\end{tabular}

Regarding the context of application, the literature analysis identified 33 topics (Table 4). Digital nudges are mostly studied in the context of online security, ecommerce, Green IS, and Social Networking Services. Further contexts listed in Table 4 found less interest among researchers and can use more empirical testing.

Finally, it is worth highlighting the recent debate on digital choice environments that focuses on the fact that all interactions happening in these environments are embedded in the physical world. Scholars conceptualize this phenomenon as a blended environment and distinguish it from digital environments [1]. They build the concept on the fact that the digital nudge influences individuals' decisions in the digital choice environment, but they perform the intended behavior in the physical world. 


\subsection{Digital component of nudging}

Of the 89 papers, most of them (57) conceptualize nudges or examine nudging theory by testing simple changes to the graphical user interface. These studies do not build on the nature of digital objects. They study nudges known from physical environments but converted into digital streams. Thus, following the concepts introduced earlier, we can call these nudges digitized, rather than digital, as they do not include properties of digital objects in their design.

Only 32 studies assume the possibility of nudging mechanisms to be transformed by functionalities granted by the digital objects' properties. In 10 articles the nudge changes its appearance or design due to individuals' behavior in the choice environment. For example, an individual performing a specific action (e.g., asking a question to a chatbot [54] or trying to write a social media post [55]) triggers the software to display a nudge adapted to that action. Thus, the bearer of the nudge interacts with the users and adapts the nudge to the individual's behavior in a simple way.

In 15 articles, the nudge adapting to an individual takes a more sophisticated form as the design of the nudge adapts to individuals' profiles, based on the user behavioral data. The digital object collects the data about the user and adjusts the nudge to a specific profile of a user, based on that data. For example, this can be a distance from an individual's home (based on geolocation data) [56] or information about an individual's friends and hobbies, accessed from Social Networking Services [57]. Thus, such nudges require a higher extent of computation, and their output can be considered personalized.
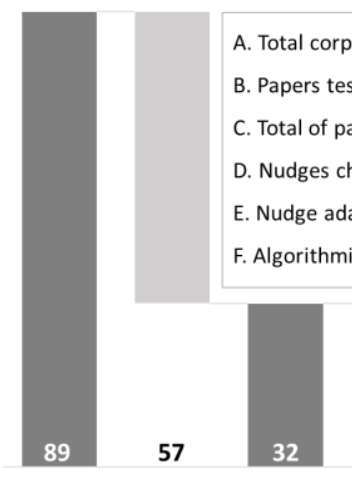

Total corpus

Nudge adapting to individuals' profiles

Figure 1. "Digital" component of nudging in the literature
Table 4. Context of application in digital nudging studies

\begin{tabular}{|c|c|c|c|c|c|}
\hline \multicolumn{2}{|c|}{ Category } & Topics & 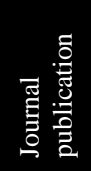 & 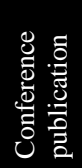 & 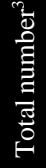 \\
\hline \multirow{8}{*}{\multicolumn{2}{|c|}{$\begin{array}{l}\text { Industry type } \\
\text { context }\end{array}$}} & $\begin{array}{l}\text { Online security / Web } \\
\text { privacy }\end{array}$ & 9 & 6 & 15 \\
\hline & & E-commerce & 5 & 9 & 14 \\
\hline & & Education & 2 & 3 & 5 \\
\hline & & Healthcare / Health IS & 2 & 2 & 4 \\
\hline & & Emergency response & 1 & 0 & 1 \\
\hline & & Public safety & 1 & 0 & 1 \\
\hline & & Charity & 0 & 1 & 1 \\
\hline & & E-politics & 0 & 1 & 1 \\
\hline \multirow{8}{*}{\multicolumn{2}{|c|}{ Tool context }} & $\begin{array}{l}\text { Social Networking } \\
\text { Services }\end{array}$ & 5 & 3 & 8 \\
\hline & & Gamification tools & 3 & 0 & 3 \\
\hline & & $\begin{array}{l}\text { Recommendation } \\
\text { systems }\end{array}$ & 2 & 0 & 2 \\
\hline & & Artificial intelligence & 1 & 0 & 1 \\
\hline & & Digital Platforms & 0 & 4 & 4 \\
\hline & & Robo-advisory & 0 & 2 & 2 \\
\hline & & Chatbot & 0 & 1 & 1 \\
\hline & & $\begin{array}{l}\text { Anthropomorphism of } \\
\text { interface }\end{array}$ & 0 & 1 & 1 \\
\hline \multirow{10}{*}{ 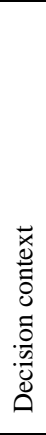 } & \multirow{7}{*}{$\frac{8}{\frac{\pi}{0}}$} & $\begin{array}{l}\text { Open innovation / Idea } \\
\text { selection }\end{array}$ & 1 & 3 & 4 \\
\hline & & $\begin{array}{l}\text { Collective Decision } \\
\text { Making }\end{array}$ & 1 & 1 & 2 \\
\hline & & Digital workplace & 0 & 2 & 2 \\
\hline & & $\begin{array}{l}\text { Business Process } \\
\text { Improvements }\end{array}$ & 1 & 0 & 1 \\
\hline & & Knowledge sharing & 1 & 0 & 1 \\
\hline & & Organizational Behavior & 0 & 1 & 1 \\
\hline & & Enterprise Architecture & 0 & 1 & 1 \\
\hline & \multirow{3}{*}{ 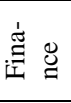 } & Crowdfunding & 1 & 2 & 3 \\
\hline & & Money-saving & 0 & 2 & 2 \\
\hline & & Financial investments & 0 & 1 & 1 \\
\hline \multirow{2}{*}{\multicolumn{2}{|c|}{$\begin{array}{l}\text { Information } \\
\text { search }\end{array}$}} & Fake news detection & 2 & 1 & 3 \\
\hline & & Information consumption & 1 & 0 & 1 \\
\hline \multirow{5}{*}{\multicolumn{2}{|c|}{ Other }} & Green IS & 2 & 8 & 10 \\
\hline & & Ethics & 2 & 2 & 4 \\
\hline & & Well-being & 1 & 0 & 1 \\
\hline & & User onboarding & 0 & 1 & 1 \\
\hline & & Customer experience & 0 & 1 & 1 \\
\hline
\end{tabular}

Finally, only seven papers theorize about the algorithmically modified nudges that adapt to the individuals based on the data coming from the individual and their environment. In these cases, the digital objects collect the data from the individual and individual's environment and pass it as an input to an algorithm. For example, Schneider and colleagues [39] predict the possibility of designing nudges based on individual's characteristics and their environment, derived from big digital data streams. The entire design of the nudge is based on the output of the algorithm's computation. Such nudges require the highest extent of

\footnotetext{
${ }^{3}$ Sums to more than 89 as some studies focus on several topics.
} 
computation and can be considered truly 'digital'. Their design requires the existence of digital objects and cannot be replicated without them. However, the idea has not been tested empirically.

\section{Discussion}

Previous research calls nudging 'digital specific phenomena' because, even if analog to the physical world, digital choice environments are better suited for influencing individuals because of being often displayed on screens, thus being highly visual $[1,40]$. However, such a view limits digital nudging to graphical choice environments and does not necessarily align with the recent debate on digital objects. The definition of choice environment envisages the possibility of the choice environment being 'physical or virtual' [23]. In the IS literature on digital nudging, there is little discussion on what the digital choice environments are or how their 'digital' properties change the phenomenon of nudging. Most previous works study digital choice environments and digital nudging as a reflection of their analog original on a screen, in line with theorizing on artificial choice environments by Buxton [22].

Referring to the earlier sections, nudges studied in this manner could be seen as 'digitized' nudges in 'digitized' choice environments, or what Hummel and colleagues call 'nudges in digital setting' [58:54], rather than truly 'digital' nudges benefiting from the nature and properties of digital objects - non-materiality and computability.

\subsection{Non-materiality of digital nudging}

In the literature, there is little discussion on what makes digital nudges 'digital' in light of the recent debate on digital objects and their non-materiality. The most complete conceptualization of the digital choice environment focuses on the fact that all interactions happening in these environments are embedded in the physical world as the individual interacts with the digital objects through their physical bearers [1]. This phenomenon is conceptualized as a blended environment and distinguished from digital environment [1]. However, building on the concept of digital objects [8], such a distinction does not picture the digital nature of digital choice environments. Because of the non-materiality of digital objects, individuals can interact with them only through their material 'bearers'. The interaction with the physical world is one of the conditions that define the existence of digital nudges as digital objects. For example, the digital choice environment, like other digital objects, can be a nonmaterial or hybrid object borne by bearers that can interact with the physical environment such that they actively shape individuals' experience in the physical environments [8]. It is because of their non-material nature that the digital choice environment interacts with the physical environment and digital nudges affect an individual's behavior in the physical world. In this perspective, such a conceptualization is in line with the concept of blended environments as the context where the decision-making and behavior happens. However, more focus on the computed nature is needed to understand how the phenomenon of nudging changes.

\subsection{Computed nature of digital nudging}

Based on the characteristics of digital objects we can claim that it is not enough to just change the interface elements to call nudging 'digital'. For example, a default nudge presented on a graphical user interface has the same underlying working principle as a default nudge presented on a piece of paper. Changing the color of a button to make it more salient in an online form is built on the same rule as making a healthy product more visible on a shelf in a grocery store. However, neither of these examples exploit the advantages of digital objects that bear these nudges. Thus, based on the conceptual background, we should, rather, call such nudging 'digitized'.

A step further from the 'digitized' nudge is the use of interactive interfaces to adapt to the individual's current behavior. For example, if the individual wants to buy an unhealthy product in an e-shop, then (and only then) a pop-up window can show up to double-check the decision with the user. Such nudging requires the digital object to interact with the individuals and use some extent of computation to adapt the nudging intervention to the individual's behavior in a simple way (e.g., based on a simple if-else condition). Such nudging, too, could be potentially executed in the physical choice environment. For example, a vendor in a local shop can react to users' facial expressions or hesitations and adjust the offer in real-time. However, in this case, the digital objects give the choice architects the undisputable advantage of scalability.

The real power of 'digital' comes from the fact that there is an algorithm behind a nudge that can modify and improve it in real-time. Nowadays, individuals turn their decisions to artificial intelligence, machine learning, and other computing technologies. This raises questions on how AI could nudge, particularly having access to data on the individuals and thus making it personalized. Using digital objects to bear nudges in digital choice environments gives a unique opportunity to adjust the nudge to individuals' behavior and context [59]. The potential use of such digital nudging is a personalized choice environment - the digital objects collect the data about the individuals' behavior from digital data streams 
and pass it to an algorithm to create a personalized profile of an individual and match nudge with each such profile.

For example, a Chinese mobile app Taobao developed by Alibaba tracks users' digital behavior and uses it as an input to feed the algorithm that analyzes user's profiles and creates a highly personalized, selfimproving interface that matches with the profile of each user [60]. What is more important, such a personalized environment gives Alibaba a unique opportunity to present nudges that are specifically tailored for each user, based on their digital footprint.

An even more interesting example of such a personalized nudge comes from Kabbex - a Dutch startup, which stretches this property even further. It offers an algorithm that creates a mood-based shopping recommendation. A face recognition software analyzes an individual's mood based on facial expressions. Depending on the result of the analysis, an algorithm adjusts the recommendation so that they match with individual's mood [61].

Finally, a small stream of literature discusses digital nudging in its full potential that could not exist without digital objects and their properties. In these cases, digital objects collect the data not only from the individual but also from the individual's environment. They pass the data as an input to an algorithm. The decision if to nudge and how to do it is based on the output of the algorithm's computation and is automatically applied by the digital object. All forms of nudging like personalized nudging, come from the fact that the algorithm can read the inputs from the environment, analyze them, and provide output to pass it back to the digital object. Then, digital nudging could be understood as nudging designed into and happening via digital objects. Such a form of nudging does not have its counterpart in the 'non-digital' environments and makes the phenomenon truly 'digital'. Thus, such a truly 'digital' nudge could take advantage of this digital nature and alter the process of nudging.

For example, we can think of an Uber and the algorithmic management it uses to nudge its drivers [62]. Uber uses nudging as an element of algorithmic control - 'the use of algorithms to monitor platform workers' behavior and ensure its alignment with the platform organization's goals' to offer high-quality service to customers [62:18]. Uber tracks driver's behavior when they use the app so that every move is tracked and analyzed in real-time. Building on the insights from these data, Uber's algorithm learns when exactly to nudge drivers and iteratively improve its attempts to influence drivers' behavior. Before introduction of these techniques, drivers complained about too many or even nagging attempts to nudge them [62]. Simple interface-based techniques did not always work. Due to algorithmic nudging, Uber improved the efficiency of its efforts and increased the engagement of its drivers.

While we call this algorithm-based nudging 'truly digital', it has not been tested empirically by IS scholars. Thus, further research could adopt this conceptualization of digital nudging and focus on studying it as nudging enabled by and integrated with digital objects, rather than 'digitized' nudging techniques. Potential studies could conduct field experiments in natural settings or simulations in which the digital object has a leading role in nudging individuals. Akin research will allow understanding not only if nudging mechanisms work in digital choice environments, but also to examine the ways these environments integrated with digital objects transform the processes of nudging.

The examples presented earlier in this section show how digital objects potentially improve the process of nudging. However, while the ethics of digital nudging is not the main focus of this paper, and recent literature discusses the topic [63, 64], digital nudging as conceptualized here requires a reflection on possible negative side of such solution. For example, what assures that the algorithm preserves the freedom of choice of individuals? With the rise of exponential coding, machine learning, and artificial intelligence, programmers are often unable to fully explain how their algorithms arrive at a decision [65]. The question of algorithmic transparency is particularly important when the outcome of an algorithm affects individuals' decisions and behaviors. It is known that algorithms can be unintentionally programmed to produce biased outcomes that are hard to explain and affect individuals' lives negatively [66]. Potentially, due to such a bias, an algorithm can limit the freedom of choice or present choice options that do not match with the best interest of an individual. Furthermore, we need a separate discussion on the privacy of data in the context of truly digital nudging [67]. How the data is collected and what happens with the data after it is used to nudge is another interesting avenue for future studies.

\section{Conclusion}

In this paper, we reviewed the literature on digital nudging as an effective way to influence individuals' behavior when they interact with digital computers. Most previous studies focused on testing if known nudging techniques work in digital choice environments, rather than examining how digital properties of said environments, enabled by digital objects, affect the process of nudging. We investigated the conceptualization of digital technology behind this phenomenon and offered a theoretical contribution to 
the literature. Namely, we presented various types of digital nudges investigated by IS scholars and placed digital nudging and digital choice environments in the current debate on digital objects.

\section{References}

[1] Lembcke, T.-B., N. Engelbrecht, A.B. Brendel, B. Herrenkind, and L.M. Kolbe, "Towards a Unified Understanding of Digital Nudging by Addressing its Analog Roots", PACIS 2019 Proceedings, X'ian, 2019.

[2] Meske, C., and I. Amojo, "Status Quo, critical reflection, and the road ahead of digital nudging in information systems research: A discussion with markus weinmann and alexey voinov", Communications of the Association for Information Systems 46, 2020, pp. 402-420.

[3] Mirsch, T., C. Lehrer, and R. Jung, "Making Digital Nudging Applicable: The Digital Nudge Design Method", ICIS 2018 Proceedings, San Francisco, 2018.

[4] Thaler, R.H., and C.R. Sunstein, Nudge: Improving Decisions About Health, Wealth, and Happiness, Penguin Group USA, New York, 2009.

[5] Gregor, S., and B. Lee-Archer, "The digital nudge in social security administration", International Social Security Review 69(3-4), 2016, pp. 63-83.

[6] Weinmann, M., C. Schneider, and J. vom Brocke, "Digital Nudging", Business \& Information Systems Engineering 58(6), 2016, pp. 433-436.

[7] Orlikowski, W.J., and C.S. Iacono, "Research Commentary: Desperately Seeking the 'IT' in IT Research-A Call to Theorizing the IT Artifact", Information Systems Research 12(2), 2001, pp. 121-134.

[8] Faulkner, P., and J. Runde, "Theorizing the Digital Object", Management Information Systems Quarterly 43(4), 2019, pp. 1279-1302.

[9] Baskerville, R.L., M.D. Myers, and Y. Yoo, "Digital first: The ontological reversal and new challenges for IS research", MIS Quarterly 44(2), 2020, pp. 509-523.

[10] Piccoli, G., J. Rodriguez, and V. Grover, "Strategic Initiatives and Digital Resources: Construct Definition and Future Research Directions”, ICIS 2020 Proceedings, Hyderabad, 2020.

[11] Yoo, Y., "Computing in Everyday Life: A Call for Research on Experiential Computing.", MIS Quarterly 34(2), 2010, pp. 213-231.

[12] Kahneman, D., “A perspective on judgment and choice: Mapping bounded rationality", American Psychologist 58(9), 2003, pp. 697-720.

[13] Kahneman, D., Attention and effort, Prentice-Hall, Englewood Cliffs, NJ, 1973.

[14] Simon, H.A., Models of man; social and rational, Wiley, Oxford, England, 1957.

[15] Ågerfalk, P.J., "Artificial intelligence as digital agency", European Journal of Information Systems 29(1), 2020, pp. 1-8.

[16] Rodriguez, J., and G. Piccoli, "Uncovering the digital ' $x$ ' phenomena in the IS field: A text analysis approach", BLED 2018 Proceedings, Bled, 2018.

[17] Edwards, W., "The theory of decision making", Psychological Bulletin 51(4), 1954, pp. 380-417.
[18] Tversky, A., and D. Kahneman, "Rational Choice and the Framing of Decisions", The Journal of Business 59(4), 1986, pp. S251-S278.

[19] Kosters, M., and J. Van der Heijden, "From mechanism to virtue: Evaluating Nudge theory", Evaluation 21(3), 2015, pp. 276-291.

[20] Payne, J.W., J.R. Bettman, and E.J. Johnson, "Behavioral decision research: A constructive processing perspective", Annual review of psychology 43(1), 1992, pp. 87-131.

[21] Kahneman, D., "Maps of Bounded Rationality: Psychology for Behavioral Economics", American Economic Review 93(5), 2003, pp. 1449-1475.

[22] Buxton, W., "Human skills in interface design", In L.W. MacDonald and J. Vince, eds., Interacting with virtual environments. Wiley, New York, 1994, 1-12.

[23] Congiu, L., and I. Moscati, "Message and Environment: a framework for nudges and choice architecture", Behavioural Public Policy 4(1), 2020, pp. 71-87.

[24] Swait, J., and W. Adamowicz, "Choice Environment, Market Complexity, and Consumer Behavior: A Theoretical and Empirical Approach for Incorporating Decision Complexity into Models of Consumer Choice", Organizational Behavior and Human Decision Processes 86(2), 2001, pp. 141-167.

[25] Dolan, P., "We can use nudges to construct our 'choice environment' to improve wellbeing", British Politics and Policy at LSE, 2011. https://blogs.lse.ac.uk/ politicsandpolicy/nudges-work/

[26] Bucher, T., C. Collins, M.E. Rollo, et al., "Nudging consumers towards healthier choices: a systematic review of positional influences on food choice", British Journal of Nutrition 115(12), 2016, pp. 2252-2263.

[27] Huang, N., P. Chen, Y. Hong, and S. Wu, "Digital Nudging for Online Social Sharing: Evidence from A Randomized Field Experiment", Hawaii International Conference on System Sciences 2018 (HICSS-51), 2018.

[28] Williams, B.O., Computing with Electricity, 1935-1945, University of Kansas, 1987.

[29] Hui, Y., "What is a Digital Object?", Metaphilosophy 43(4), 2012, pp. 380-395.

[30] Tilson, D., K. Lyytinen, and C. Sørensen, "Research Commentary-Digital Infrastructures: The Missing IS Research Agenda", Information Systems Research 21(4), 2010, pp. 748-759.

[31] Gassmann, O., K. Frankenberger, and M. Csik, The St. Gallen Business Model Navigator, University of St Gallen, 2014.

[32] Gray, J., and B. Rumpe, "Models for digitalization", Software \& Systems Modeling 14(4), 2015, pp. 13191320.

[33] Moore, G.E., "Cramming more components onto integrated circuits", Electronics 38(8), 1965, pp. 114.

[34] Kallinikos, J., A. Aaltonen, and A. Marton, "The Ambivalent Ontology of Digital Artifacts", MIS Quarterly 37(2), 2013, pp. 357-370.

[35] Negroponte, N., Being Digital, Vintage Books, 1995.

[36] Yoo, Y., R.J. Boland, K. Lyytinen, and A. Majchrzak, "Organizing for Innovation in the Digitized World", Organization Science 23(5), 2012, pp. 1398-1408. 
[37] Dourish, P., Where the Action Is: The Foundations of Embodied Interaction, The MIT Press, Cambridge, Mass., 2004.

[38] McCullough, M., Digital Ground: Architecture, Pervasive Computing, and Environmental Knowing, The MIT Press, Cambridge, Mass, 2005.

[39] Schneider, C., M. Weinmann, and J.V. Brocke, "Digital nudging: Guiding online user choices through interface design", Communications of the ACM 61(7), 2018, pp. 67-73.

[40] Benartzi, S., The Smarter Screen: Surprising Ways to Influence and Improve Online Behavior, Penguin, 2015.

[41] Lee, B.-K., J.-Y. Hong, and W.-N. Lee, "How Attitude toward the Web Site Influences Consumer Brand Choice and Confidence While Shopping Online", Journal of Computer-Mediated Communication 9(JCMC923), 2004.

[42] Ariely, D., "Controlling the information flow: Effects on consumers' decision making and preferences", Journal of consumer research 27(2), 2000, pp. 233-248.

[43] Rometty, G., "Digital today, cognitive tomorrow", MIT Sloan Management Review 58(1), 2016, pp. 28.

[44] Rzepka, C., and B. Berger, "User Interaction with AIenabled Systems: A Systematic Review of IS Research", ICIS 2018 Proceedings, San Francisco, 2018.

[45] Webster, J., and R.T. Watson, "Analyzing the past to prepare for the future: Writing a literature review", MIS Quarterly 26(2), 2002, pp. 3.

[46] Vom Brocke, J., A. Simons, B. Niehaves, et al., "Reconstructing the giant: On the importance of rigour in documenting the literature search process.", ECIS, (2009), 2206-2217.

[47] Cooper, H.M., "Organizing knowledge syntheses: A taxonomy of literature reviews", Knowledge, Technology \& Policy 1(1), 1988, pp. 104-126.

[48] "Academic Journal Guide 2018", Chartered Association of Business Schools. https://charteredabs.org/academicjournal-guide-2018/

[49] Maedche, A., C. Legner, A. Benlian, et al., "AI-Based Digital Assistants: Opportunities, Threats, and Research Perspectives", Business and Information Systems Engineering 61(4), 2019, pp. 535-544.

[50] Williams, M., J.R.C. Nurse, and S. Creese, "(Smart)Watch Out! encouraging privacy-protective behavior through interactive games", International Journal of Human Computer Studies 132, 2019, pp. 121137.

[51] Williams, M., J.R.C. Nurse, and S. Creese, "Smartwatch games: Encouraging privacy-protective behaviour in a longitudinal study", Computers in Human Behavior 99, 2019, pp. 38-54.

[52] Sengupta, A., A. Bhattacherjee, and K. Dutta, "Information Technology Interventions in Cardiac Rehabilitation: A Theory Driven Approach", ICIS 2020 Proceedings, Hyderabad, 2020.

[53] Adam, M., and M. Pecorelli, "Recommendations In Augmented Reality Applications - The Effect Of Customer Reviews And Seller Recommendations On Purchase Intention And Product Selection", Research Papers, 2018.
[54] Rodriguez, J., G. Piccoli, and M. Bartosiak, "Nudging the Classroom: Designing a Socio-Technical Artifact to Reduce Academic Procrastination", Proceedings of the 52nd Hawaii International Conference on System Sciences, (2019).

[55] Alemany, J., E. del Val, J. Alberola, and A. GarcíaFornes, "Enhancing the privacy risk awareness of teenagers in online social networks through softpaternalism mechanisms", International Journal of Human Computer Studies 129, 2019, pp. 27-40.

[56] Huang, Y., C. White, H. Xia, and Y. Wang, “A computational cognitive modeling approach to understand and design mobile crowdsourcing for campus safety reporting", International Journal of Human Computer Studies 102, 2017, pp. 27-40.

[57] (Alex) Wang, C., X. (Michael) Zhang, and I.-H. Hann, "Socially nudged: A quasi-experimental study of friends' social influence in online product ratings", Information Systems Research 29(3), 2018, pp. 641-655.

[58] Hummel, D., and A. Maedche, "How effective is nudging? A quantitative review on the effect sizes and limits of empirical nudging studies", Journal of Behavioral and Experimental Economics 80, 2019, pp. 47-58.

[59] Johnson, E.J., S.B. Shu, B.G.C. Dellaert, et al., "Beyond nudges: Tools of a choice architecture", Marketing Letters 23(2), 2012, pp. 487-504.

[60] Content Commerce Insider, "Future Tech China: How Taobao Turned Product Listings into Entertainment", 2021.https://contentcommerceinsider.substack.com/p/fut ure-tech-china-how-taobao-turned

[61] "How IT Works - kabbex", https://kabbex.com/how-itworks/

[62] Möhlmann, M., L. Zalmanson, O. Henfridsson, and R.W. Gregory, "Algorithmic management of work on online labor platforms: when matching meets control", MIS Quarterly, Forthcoming.

[63] Lembcke, T.-B., N. Engelbrecht, A.B. Brendel, and L. Kolbe, "To Nudge or Not to Nudge: Ethical Considerations of Digital Nudging Based on its Behavioral Economics Roots", Proceedings of the 27th European Conference on Information Systems (ECIS), (2019).

[64] Meske, C., and I. Amojo, "Ethical Guidelines for the Construction of Digital Nudges", Proceedings of the 53rd Hawaii International Conference on System Sciences, (2020).

[65] Ananny, M., and K. Crawford, "Seeing without knowing: Limitations of the transparency ideal and its application to algorithmic accountability", New Media \& Society 20(3), 2018, pp. 973-989.

[66] Cossins, D., "Discriminating algorithms: 5 times AI showed prejudice", New Scientist. https://www.newscientist.com/article/2166207discriminating-algorithms-5-times-ai-showed-prejudice/

[67] Wisniewski, P.J., B.P. Knijnenburg, and H.R. Lipford, "Making privacy personal: Profiling social network users to inform privacy education and nudging", International Journal of Human Computer Studies 98, 2017, pp. 95108. 